\title{
Water addition, evaporation and water holding capacity of poultry litter
}

\author{
Mark W. Dunlop a,b,c,*, Patrick J. Blackall ${ }^{\text {c,d }}$, Richard M. Stuetz ${ }^{\mathrm{b}}$ \\ a Department of Agriculture and Fisheries, QLD Government, Toowoomba 4350, Australia \\ b University of NSW, School of Civil and Environmental Engineering, Sydney 2052, Australia \\ c Poultry CRC, PO Box U242, University of New England, Armidale, NSW 2351, Australia \\ d The University of Queensland, QLD Alliance for Agriculture and Food Innovation, Dutton Park, Brisbane 4102, Australia
}

\section{H I G H L I G H T S}

- Water added daily to litter by meat chickens was estimated using an equation

- Water added to litter from excreta and spillage can be as much as $3.2 \mathrm{~L} / \mathrm{m}^{2} /$ day

- Water holding capacity of litter increases during a grow-out cycle

- Water evaporation rate depends on litter moisture content and air speed

\section{A R T I C L E I N F O}

\section{Article history:}

Received 23 April 2015

Received in revised form 4 August 2015

Accepted 16 August 2015

Available online $\mathrm{xxxx}$

Editor: Simon Pollard

\section{Keywords:}

Broiler

Litter moisture content

Wet litter

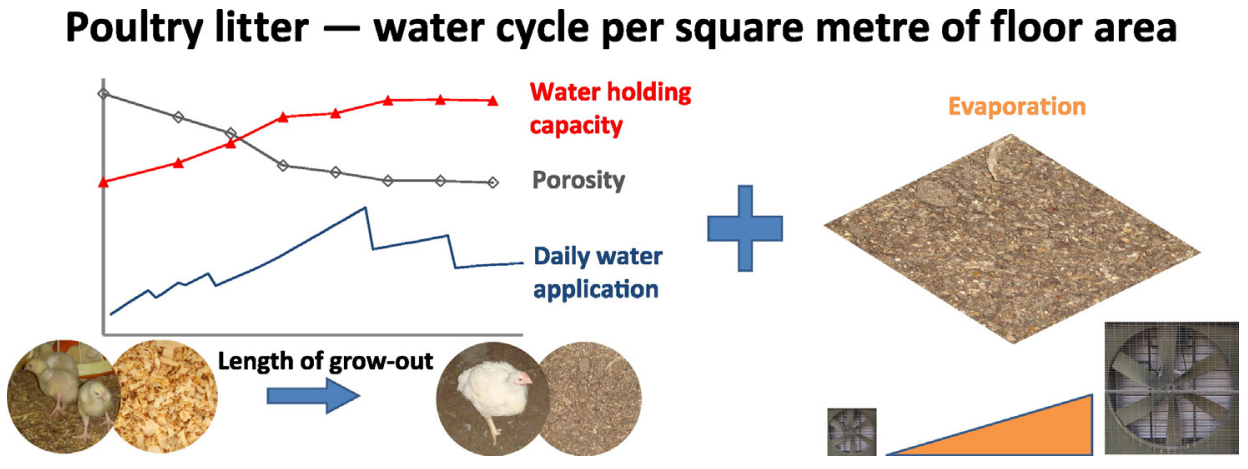

\begin{abstract}
A B S T R A C T
Litter moisture content has been related to ammonia, dust and odour emissions as well as bird health and welfare. Improved understanding of the water holding properties of poultry litter as well as water additions to litter and evaporation from litter will contribute to improved litter moisture management during the meat chicken grow-out. The purpose of this paper is to demonstrate how management and environmental conditions over the course of a grow-out affect the volume of water A) applied to litter, B) able to be stored in litter, and C) evaporated from litter on a daily basis. The same unit of measurement has been used to enable direct comparison-litres of water per square metre of poultry shed floor area, $\mathrm{L} / \mathrm{m}^{2}$, assuming a litter depth of $5 \mathrm{~cm}$. An equation was developed to estimate the amount of water added to litter from bird excretion and drinking spillage, which are sources of regular water application to the litter. Using this equation showed that water applied to litter from these sources changes over the course of a grow-out, and can be as much as $3.2 \mathrm{~L} / \mathrm{m}^{2} /$ day. Over a 56 day growout, the total quantity of water added to the litter was estimated to be $104 \mathrm{~L} / \mathrm{m}^{2}$. Litter porosity, water holding capacity and water evaporation rates from litter were measured experimentally. Litter porosity decreased and water holding capacity increased over the course of a grow-out due to manure addition. Water evaporation rates at $25{ }^{\circ} \mathrm{C}$ and $50 \%$ relative humidity ranged from 0.5 to $10 \mathrm{~L} / \mathrm{m}^{2} /$ day. Evaporation rates increased with litter moisture content and air speed. Maintaining dry litter at the peak of a grow-out is likely to be challenging because evaporation rates from dry litter may be insufficient to remove the quantity of water added to the litter on a daily basis. Crown Copyright @ 2015 Published by Elsevier B.V. All rights reserved.
\end{abstract}

\footnotetext{
* Corresponding author at: Department of Agriculture and Fisheries, 203 Tor Street, Toowoomba, 4350 Qld Australia. E-mail address: mark.dunlop@daf.qld.gov.au (M.W. Dunlop).
} 


\section{Introduction}

Meat chickens are commonly raised in open-plan sheds with a litter covered floor. Litter is a mixture of bedding materials and manure that is used to provide a cushioning and insulating barrier between the birds and the ground. It needs to absorb moisture, dry readily, and allows birds to display natural behaviour such as scratching and dust-bathing (Shepherd and Fairchild, 2010; Collett, 2012). Control of litter moisture is complex and challenging due to environmental, economic, engineering and animal husbandry constraints (Tucker and Walker, 1992).

Litter moisture content has been found to influence ammonia emissions (Elliott and Collins, 1982; Liu et al., 2007; Miles et al., 2011), odours (Clarkson and Misselbrook, 1991; Murphy et al., 2014), dust (Roumeliotis et al., 2010), and health issues such as foot pad dermatitis (Bilgili et al., 2009; de Jong et al., 2012). Microbial populations flourish when litter has a moisture content greater than 35-40\% (mass water/ mass of litter), which can have consequences including increased odour production and greater risks to bird health and food safety (Eriksson De Rezende et al., 2001; Agnew and Leonard, 2003; Wadud et al., 2012). Moisture content also affects litter physical and handling properties including compressibility, compaction and cohesion (Agnew and Leonard, 2003; Bernhart and Fasina, 2009; Bernhart et al., 2010). Increased moisture content and compaction reduces thermal insulating properties and porosity resulting in anaerobic conditions and decreased $\mathrm{pH}$ (Agnew and Leonard, 2003).

Within a meat chicken shed, water is routinely added to the litter through excretion (faeces and urine, which in poultry are excreted simultaneously), spillage from drinkers, condensation, shed leaks and absorption from the air. Collett (2012) estimated that a flock of 20,000 birds can excrete up to $2500 \mathrm{~L}$ of water per day onto the litter.

Water is removed from litter by evaporation. Water removal can be enhanced with ventilation and litter turning (Collett, 2012). Specific knowledge of evaporation rates from litter is important for managing litter moisture but can also be related to diffusion rates of gases such as ammonia and other odorants from litter. Evaporation of water has been found to be representative of the emission of gas-phase controlled volatile organic compounds (VOCs), which includes many of the odorants identified as contributing to odour impacts (Hudson and Ayoko, 2008; Parker et al., 2010, 2013). The advantage of using water evaporation (water flux) instead of VOCs is the relative ease, low cost and accuracy of measuring water evaporation (Parker et al., 2013).

Understanding the relationships between water addition, storage and evaporation throughout a grow-out (otherwise known as a growout cycle or period; batch; or production cycle) will improve litter moisture management. The purpose of this paper is to highlight the volume of water that is A) applied daily to litter, B) able to be stored in litter, and C) evaporated daily from litter over the course of a growout and with different environmental conditions and management. In this paper, water quantities are expressed in the same unit of measurement for direct comparison (litres of water per square metre of poultry shed floor area, $\mathrm{L} / \mathrm{m}^{2}$, assuming a litter depth of $5 \mathrm{~cm}$ ).

\section{Materials and methods}

Daily water additions to litter from bird excretion and normal drinking spillage were calculated using an equation that drew on empirically derived relationships between feed intake, water usage and water losses for commercial meat chickens. In separate experimental work, the volume of water stored in litter per square metre of floor area, water evaporation rates and litter porosity were measured.

\subsection{Calculating litter wetting due to excretion and normal drinking spillage}

An equation was developed to estimate daily application of water to litter from excretion and normal drinking spillage (Eq. (1)). It includes water inputs $\left(w_{\text {drinking }}, w_{\text {feed }}\right.$ and $\left.w_{\text {metabolic }}\right)$, retention $\left(w_{\text {growth }}\right)$ and evaporation losses $\left(w_{\text {latent }}\right)$ from each bird plus adjustments to account for stocking density, percentage of shed in use (relevant for part-shed brooding) and percentage of the flock remaining in the shed (relevant for when a percentage of the flock is harvested for slaughter during the grow-out). Water applied to litter was calculated on a square metre $\left(\mathrm{m}^{2}\right)$ basis (assuming a litter depth of $5 \mathrm{~cm}$ ) to enable direct comparison of water addition to litter, storage within litter and evaporation from litter. Using this equation requires assumptions that normal spillage is small compared to the amount of water consumed and that the birds are healthy, have an optimal diet, and are in a thermo-neutral environment.

The following production values were used in this study. These values are commonly used on farms in the senior author's region, but any reasonable production values can be used in the calculations. Stocking density used in this example was $17 \mathrm{birds} / \mathrm{m}^{2}$, with allowable maximum live mass density limited to $36 \mathrm{~kg} / \mathrm{m}^{2}$. The stocking density was varied during the grow-out to accommodate partial shed brooding and thinning. Partial-shed brooding in this example included using only $50 \%$ of the shed for days $1-6$ of the grow-out, $66 \%$ of the shed for days $7-10$ and $75 \%$ of the shed was used for days $11-14$. This study also included flock thinning (a production process where a portion of the flock is removed from the shed for slaughter) by removing $33 \%$ of the flock on day 35, and 33\% of the remaining flock on day 46 to maintain live mass density under $36 \mathrm{~kg} / \mathrm{m}^{2}$, with all birds removed for slaughter at the end of the grow-out on day 56. Feed consumption and growth rate data were averaged from as-hatched data for Ross 308 and Cobb500 ${ }^{\mathrm{TM}}$ breeds.

$w_{\text {litter }}=\left(w_{\text {drinking }}+w_{\text {feed }}+w_{\text {metabolic }}-w_{\text {growth }}-w_{\text {latent }}\right) \times \rho_{\text {stocking }} \div P_{\text {shed }} \times f_{\text {remaining }}$

where:

$w_{\text {litter }}$ is the water applied to litter through bird excretion and normal drinking spillage $\left(\mathrm{L} / \mathrm{m}^{2} /\right.$ day)

$w_{\text {drinking }}$ is the water used in the shed for drinking (including spillage) by each bird (L/bird/day) (Eq. (4))

$w_{\text {feed }} \quad$ is the water ingested by birds in the feed ( $\mathrm{L} / \mathrm{bird} /$ day) (assumed that feed has 10\% moisture content, $100 \mathrm{~g} / \mathrm{kg}$ 'as-fed' feed)

$w_{\text {metabolic }}$ is the water released during metabolism and available for excretion (L/bird/day) (Eq. (5))

$w_{\text {growth }}$ is the amount of water retained by the birds (L/bird/day) (assumed water accounts for $70 \%$ of daily growth)

$w_{\text {latent }}$ is the water evaporated from the bird during thermoregulation (i.e. panting and losses through the skin) (L/ bird/day)-under thermo neutral conditions this is assumed to be half of total available water: $w_{\text {latent }}=$ $0.5 \times\left(w_{\text {drinking }}+w_{\text {feed }}+w_{\text {metabolic }}-w_{\text {growth }}\right)$

$\rho_{\text {stocking }}$ is the stocking density for the entire shed floor area (birds $/ \mathrm{m}^{2}$ )

$P_{\text {shed }} \quad$ is the percentage of the shed in use in the case of part-shed brooding (\%)

$f_{\text {remaining }}$ is the percentage of flock remaining after each thinning (\%).

\subsubsection{Estimating daily water consumption}

Water consumption was related to feed intake using the water:feed ratio over the course of a grow-out ( $w f r$, total water used in drinker lines divided by total feed consumed). The water used in drinker lines inherently includes water consumed by the birds plus normal drinking spillage. This ratio is typically $1.8 \mathrm{~L} / \mathrm{kg}$ but can vary from 1.5 to $2.0 \mathrm{~L} / \mathrm{kg}$ (Feddes et al., 2002; Collett, 2007; Manning et al., 2007). The water:feed ratio increases with temperature (Manning et al., 2007), stocking density (Feddes et al., 2002) as well as certain dietary imbalances, feed ingredients and health issues (Collett, 2012). It is also affected by type of drinker, with nipple drinkers (without evaporation cups) producing the lowest ratio (Manning et al., 2007). 
The water:feed intake ratio varies during a grow-out. Williams et al. (2013) measured water usage in commercial broiler sheds using nipple drinker systems (combination of Lubing Systems, Cleveland, TN; and Cumberland Poultry Systems, Assumption, IL). Water intake measured in this way inherently includes normal drinking spillage. Williams et al. (2013) demonstrated that for days 7-42 of a grow-out, daily water:feed ratio $\left(w f_{\text {daily }}\right.$, which is the amount of water used in drinking lines on a particular day divided by the mass of feed consumed on that day) reduced from 2.53 on day 10 to $1.73-1.83$ after day 25 for 2010-2011 Cobb ${ }^{\mathrm{TM}}$ strain commercial flocks (Fig. 1). The daily water:feed ratio did not show a clear trend prior to day 10 , so in the current analysis it was assumed to have a constant value of 2.53. After 42 days, it was assumed that the water:feed ratio remained constant. This assumption was supported by water consumption data published by Watkins and Tabler (2009) when used in conjunction with published feed consumption data for the appropriate breed (Cobb500'TM).

To calculate the daily water:feed ratio, a relationship was established between the daily water:feed ratio and the grow-out water:feed ratio (Eq. (2)), using a multiplier $m$ (Eq. (3)) based on data by Williams et al. (2013). This allows an appropriate grow-out water:feed ratio to be selected in anticipation of changes to growing conditions. The water:feed ratio for a grow-out is also affected by the batch length due to higher water:feed ratio at the beginning and a greater quantity of feed and water consumed during the later stages.

$w f r_{\text {daily }}=w f r \times m$

where:

$w f r_{\text {daily }} \quad$ is the daily water:feed ratio $(\mathrm{L} / \mathrm{kg})$

$w f r \quad$ is the grow-out water feed ratio $(\mathrm{L} / \mathrm{kg})$ for days $1-56$

$m \quad$ is the multiplier applied to the grow-out water:feed ratio to calculate the daily water:feed ratio (Eq. (3)).

For $d<9, \quad m=1.385$

For $9 \leq d<32, \quad m=-2.7226 \times 10^{-5} \times d^{3}+2.7500 \times 10^{-3} \times d^{2}$

For $d \geq 32, \quad m=0.975$

$$
-9.2711 \times 10^{-2} \times d+2.0205
$$

where:

$d \quad$ is the day of the grow-out (days)

$m \quad$ is the multiplier applied the grow-out water:feed ratio to calculate the daily water:feed ratio that was derived from data in Williams et al. (2013).

The amount of water consumed daily by each bird was calculated using readily available daily feed consumption per bird data for

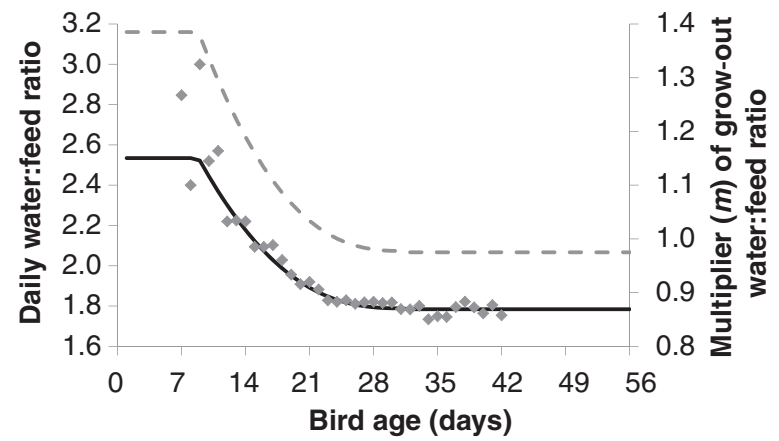

-Williams et al. (2013) -Predicted - Multiplier

Fig. 1. Subset of daily water:feed ratio ( $w f r_{\text {daily }}$ ) from Williams et al. (2013) for '2010-2011 flocks', multiplier $(m)$ of grow-out used to calculate $w f r_{\text {daily }}$ from the grow-out water:feed ratio ( $w f r)$, and predicted $w f r_{\text {daily }}$ assuming $w f r$ of $1.83\left(r^{2}=0.94\right.$ for days $\left.10-42\right)$. commercial breeds (Eq. (4)).

$w_{\text {drinking }}=w f r_{\text {daily }} \times f c_{\text {daily }}$

where:

$w_{\text {drinking }}$ is the water consumed by each bird (L/bird/day)

$w f r_{\text {daily }}$ is the daily water:feed ratio (L/kg) (from Eq. (2))

$f c_{\text {daily }} \quad$ is the daily feed consumption ( $\left.\mathrm{kg} / \mathrm{bird} / \mathrm{day}\right)$.

2.1.2. Estimating water ingested with feed and released during metabolism

Feed contains approximately $10 \%$ moisture content $(100 \mathrm{~g} / \mathrm{kg}$ 'as-fed' feed) (Collett, 2012) therefore water ingested with feed was estimated using published daily feed consumption data.

In addition to water directly ingested in feed, metabolic water is released from the feed as it is metabolised by the bird. Metabolic water production (Eq. (5)) is limited by diet formulation (33.44 g/MJ of dietary energy) (Collett, 2012). Dietary energy in feed for commercial broiler feeds is nominally $12.65-13.40 \mathrm{MJ} / \mathrm{kg}$ (Aviagen Inc., 2014).

$w_{\text {metabolic }}=33.44 \div 1000 \times E_{\text {dietary }} \times f c_{\text {daily }}$

where:

$w_{\text {metabolic }}$ is the water released during metabolism and available for excretion ( $\mathrm{L} / \mathrm{bird} /$ day)

$E_{\text {dietary }} \quad$ is dietary energy of the feed (MJ)

$f c_{\text {daily }} \quad$ is the daily feed consumption ( $\left.\mathrm{kg} / \mathrm{bird} / \mathrm{day}\right)$.

2.1.3. Estimating water retained during bird growth or evaporated for temperature regulation

Some of the water ingested by birds will not be available for excretion on the litter. It was assumed that water accounts for $70 \%$ of daily growth rate (Goldstein and Skadhauge, 2000) and was therefore not available for excretion.

Meat chickens also use water to regulate body temperature. They remove latent energy from their body by evaporating water through panting and passive losses through the skin (Yahav et al., 2004; Collett, 2012). Collett (2012) estimated that evaporative losses were approximately half of total water losses during thermoneutral conditions, leaving the other half to be excreted as liquid onto the litter. However, during times of heat stress, evaporation losses can account for as much as $80 \%$ of total water losses, leaving only $20 \%$ available for excretion as liquid. Commercial meat chickens housed in tunnel ventilated sheds are likely to be close to thermo-neutrality so it was assumed that $50 \%$ of total water losses would be excreted onto the litter.

\subsection{Water holding capacity, porosity and evaporation rate}

Water holding capacity, porosity and evaporation rates for litter were measured to enable direct comparison with water addition (Eq. (1)) on a square area basis. The objective of this comparison was to see if the physical properties of litter were changing during a growout in ways that assist or hinder litter moisture management.

\subsubsection{Farm description and litter collection}

Litter samples were collected at weekly intervals from a tunnel ventilated shed stocked with 39,870 Ross 308 meat chickens. The shed had a floor area of $2055 \mathrm{~m}^{2}$ resulting in an initial stocking density of 19.4 birds $/ \mathrm{m}^{2}$. Fresh pine shavings were used at the start of the batch to a depth of $5 \mathrm{~cm}$. Part shed brooding was used, with day old chicks being restricted to $50 \%$ of the floor area (the brooding section) before being allowed to access more of the shed.

Litter used for analysis was sub-sampled from the brooding section (so all litter collected on a sampling day had a similar opportunity for manure accumulation). Litter was collected from three trenches dug 
in the litter widthwise across the shed. Trenches were $75-100 \mathrm{~mm}$ wide and were equally spaced along the length of the brooding section. The length of each trench was half the shed width, extending from the centre of the shed to one side wall, which was randomly chosen. Litter from all three trenches was placed in a container where it was mixed with a shovel before the sub-sample was collected. Litter was transported in a sealed $20 \mathrm{~L}$ bucket for analysis.

\subsubsection{Measuring water holding capacity and porosity}

AS 3743-2003 (appendix B method) (Standards Australia, 2003) was used to determine the water holding capacity and porosity of litter samples. In brief, custom apparatus, as described in the Standard, was used comprising two pieces of PVC tube (internal diameter $8.7 \mathrm{~cm}$, length $12.0 \mathrm{~cm}$ ), one capped on the bottom and the second adapted so it could fit snugly over the top of the first piece (bottom tube and top tube, respectively). Drain holes were drilled in the bottom cap. The volume of the bottom tube was calibrated by filling the tube with water and gravimetrically determining the volume of water added. Litter was pre-conditioned to $45-55 \%$ moisture content and then poured into the top of the tube (both pieces joined together at this stage) until the top section was at least half full. The tubes and moistened litter were dropped 5 times from a height of $5 \mathrm{~cm}$ to settle the litter. The apparatus was soaked three times in a container of water so that the entire litter sample was completely submerged. The top section of tube and excess litter was carefully removed and the surface of litter levelled in the bottom tube. This was then lowered into water until water was level with the top surface of the litter and tube. The drain holes were blocked as the apparatus was removed from the water. Water was drained for up to $60 \mathrm{~min}$ into a pre-weighed container. The entire saturated litter sample was then poured into a pre-weighed sample dish and dried at $65{ }^{\circ} \mathrm{C}$ until it reached stable weight. Water holding capacity was calculated (Eq. (6)) in units $\mathrm{L} / \mathrm{m}^{2}$ assuming litter depth of $5 \mathrm{~cm}$ to enable direct comparison with water application rates calculated using Eq. (1). Litter moisture content when saturated was also calculated (mass of water/mass of litter sample, given as a percentage). Porosity was calculated using Eq. (7).

Water holding capacity $=\left(M_{w}-M_{d}\right) \div V \times 50$

where:

Water holding capacity is the volume of water per square metre $\mathrm{L} / \mathrm{m}^{2}$ (assuming $1 \mathrm{~L}=1 \mathrm{~kg}$ of water and $5 \mathrm{~cm}$ of litter depth)

$M_{w} \quad$ is the mass of the saturated litter in the bottom tube ( $\mathrm{kg}$ )

$M_{d} \quad$ is the oven dry mass of the litter in the bottom tube ( $\mathrm{kg}$ )

$V \quad$ is the volume of the bottom tube (L)

50 is the volume of litter per square metre at $5 \mathrm{~cm}$ depth $\left(\mathrm{L} / \mathrm{m}^{2}\right)$.

Air filled porosity $=V_{\text {drained }} \div V \times 100$

where:

$V_{\text {drained }} \quad$ is the volume of water drained from the mix (L)

$V \quad$ is the volume of the sample (the volume of the bottom tube) (L).

\subsubsection{Measuring evaporation rates}

A custom method was developed to measure the evaporation rate of water from litter samples. The goal was to quantify the change in evaporation potential of litter during a grow-out (due to changes in manure content and litter structural change), with increasing litter moisture content, and increasing air speed. As such, the method involved placing litter samples with defined volume and surface area (3 repetitions each of $10 \%, 22.5 \%, 35 \%, 47.5 \%$ and $60 \%$ moisture content) in custom wind tunnels (described below; 1 tunnel each with wind speed 0.5, 1.0, 1.5 and $2.0 \mathrm{~m} / \mathrm{s}$ ) within a temperature and humidity controlled cabinet (model TRH-460-SD, Thermoline Scientific, Smithfield, Australia, temperature range $10-60 \pm 1.2{ }^{\circ} \mathrm{C}$ and relative humidity range $10-90 \%$ with $4 \%$ variability). The experimental procedure was repeated approximately weekly on progressively older litter samples (collected day $10,17,24,31,38,45$ and 52 of the grow-out). Testing was replicated $(n=2)$ for each of these litter samples. Testing was also conducted using water to enable comparison between evaporation from a free water surface and litter (water was used as an experimental reference material). Jars of water were handled in the same manner as the litter samples and the testing was replicated $(n=5)$. The temperature and humidity controlled cabinet provided reproducible testing conditions.

Custom wind tunnels (485 mm wide $\times 475 \mathrm{~mm}$ long $\times$ were $100 \mathrm{~mm}$ high) were constructed from galvanised sheet metal (Fig. 2). Airflow was provided by five fans ( $92 \mathrm{~mm}$ diameter, maximum airflow $0.035 \mathrm{~m}^{3} / \mathrm{s}$, Multicomp MC36332). Variable voltage power supplies (TENMA $®$ model 72-10481, 0-30 V) was used to control the rotational speed of the fans to change the airflow rate as required in the wind tunnels. Flow straightening sections were installed on each end of the test-chamber section of the wind tunnels to reduce air turbulence and rotation. Sample jars were positioned using an evenly spaced grid. Each wind tunnel had a base section that enabled the top of sample jars to be aligned with the bottom of the wind tunnel. Sample jars were evenly spaced within the wind tunnel using a grid pattern.

Different moisture contents (10\%, 22.5\%, 35\%, 47.5\% and 60\%) were achieved by drying litter at $65{ }^{\circ} \mathrm{C}$ and then adding the required amount of water. After water was added, the samples were mixed, rested for $24 \mathrm{~h}$ in a sealed container and then mixed again prior to testing.

Litter was placed into pre-weighed plastic sample jars (50 mm deep and $41 \mathrm{~mm}$ diameter). Jars were over-filled and then the side of the jar was tapped 5 times allowing the litter to settle into the jar. Any excess was carefully scraped off the top, leaving the litter sample level with the top of the jar. Each jar was weighed and placed in a randomly determined position in the wind tunnels. Each wind tunnel contained three repetitions of all five moisture content samples.

Wind tunnels were placed into the temperature and humidity controlled cabinet, which was pre-conditioned to the required test conditions $\left(25^{\circ} \mathrm{C}, 50 \%\right.$ relative humidity). Power was then supplied to each wind tunnel simultaneously. After $3 \mathrm{~h}$ of drying, each sample jar was re-weighed to determine the moisture loss. Moisture loss from each jar was adjusted to a daily average value for further calculations. Evaporation rates were calculated in terms of litres of evaporation per square metre per day $\left(\mathrm{L} / \mathrm{m}^{2} /\right.$ day $)$.

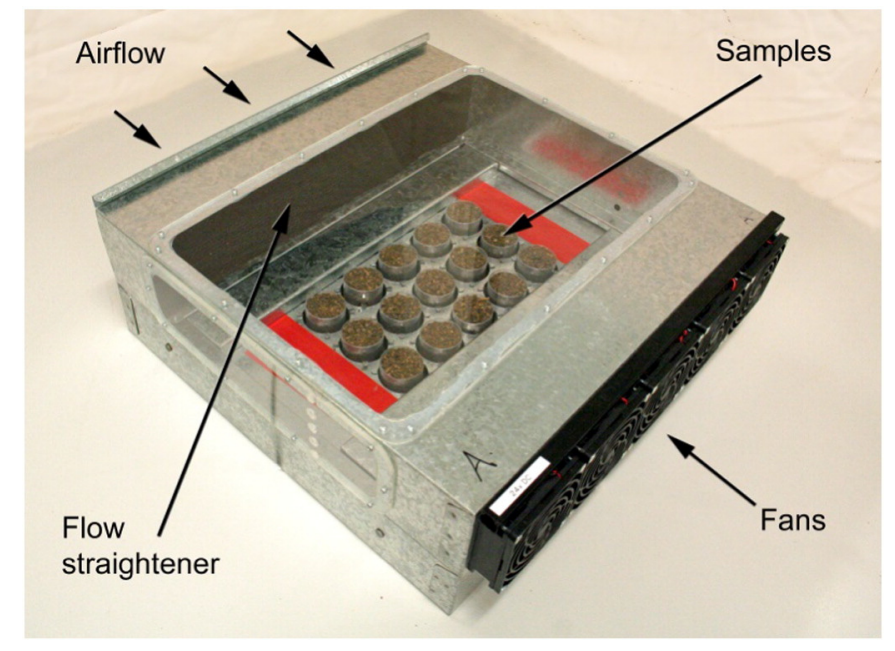

Fig. 2. Custom wind tunnel used to measure evaporation from litter (acrylic panels provide a view of the inside). 


\subsection{Data analysis}

Data from the experiments to measure porosity and evaporation rates were analysed using double split-plot ANOVA tests with Genstat (VSN, 2014).

\section{Results and discussion}

\subsection{Litter wetting due to bird excretion and normal drinking spillage during} a grow-out

Fig. 3 shows the daily rate of litter wetting due to bird excretion and normal drinking spillage calculated using Eq. (1) and the assumptions outlined in the methodology section. Daily water deposition ranged from $0.5 \mathrm{~L} / \mathrm{m}^{2}$ on day 1 to a maximum of $3.2 \mathrm{~L} / \mathrm{m}^{2}$ on day 35 . Over the course of a 56 day grow-out the total quantity of water excreted onto the litter was $104 \mathrm{~L} / \mathrm{m}^{2}$.

Water deposition rates decreased after day 35 due to assumptions about thinning regimes. For the first 14 days of the grow-out, restriction of the flock into the brooding section of the shed, in addition to higher water:feed intake, increased the rate of water deposition. Interestingly, the daily water deposition rate on day 47 following the second thinning is similar to the water deposition rate on day $14\left(1.7 \mathrm{~L} / \mathrm{m}^{2} /\right.$ day compared to $1.6 \mathrm{~L} / \mathrm{m}^{2} /$ day) despite the live mass density being about twice as much $\left(24 \mathrm{~kg} / \mathrm{m}^{2}\right.$ on day 47 compared to $11 \mathrm{~kg} / \mathrm{m}^{2}$ on day 14). These results suggest that water deposition rates and litter water content should be considered with regard to daily ventilation requirements to ensure the water added daily to the litter is evaporated.

There are limited published examples of water excretion/spillage estimates for comparison. Collett (2012) estimated that a flock of 20,000 meat chickens excretes $2500 \mathrm{~L}$ of water daily onto the litter at maximum density (assumed to be day 35 of the grow-out). In comparison, we estimated $3800 \mathrm{~L}$ of water would be added to the litter. Bolan et al. (2010) estimated total manure production for 35 and 49 day old meat chickens to be $4 \mathrm{~kg}$ and $6 \mathrm{~kg}$, respectively, with an assumption that moisture content of excreted manure is $90 \%$. Using these values, the total water excreted up to 35 and 49 days is approximately $3.7 \mathrm{~kg}$ and $7.0 \mathrm{~kg}$, respectively per bird, which is similar to our estimates ( $3.6 \mathrm{~kg}$ at day 35 and $5.5 \mathrm{~kg}$ at day 49). Discrepancies between our findings and previously published estimates of water deposition

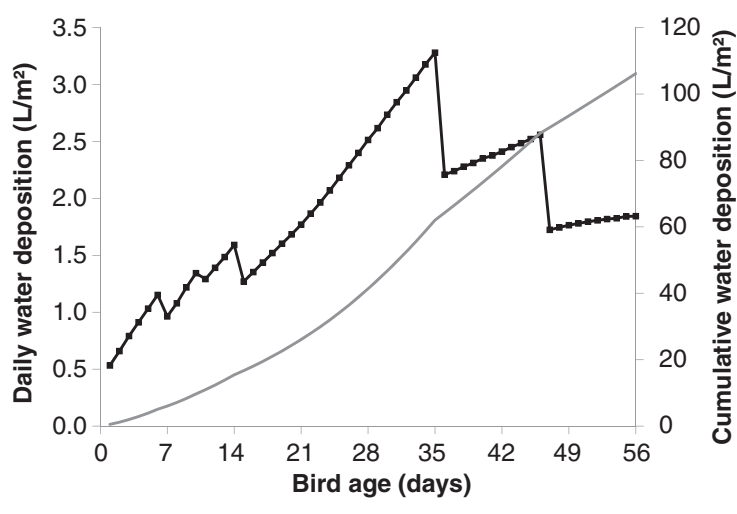

Fig. 3. Daily and cumulative deposition of water to litter during a grow-out based on the following assumptions: feed consumption of as-hatched birds (averaged for Ross 308 and Cobb500 ${ }^{\mathrm{TM}}$ breeds); water:feed intake ratio for the grow-out was 1.83; 70\% of growth rate was water retained in the bird; $50 \%$ of total water lost from the bird was excreted as liquid onto the litter; stocking density 17.0 birds $/ \mathrm{m}^{2}$; birds restricted to $50 \%$ of shed floor area until day $6,66 \%$ until day $10,75 \%$ until day $14 ; 33 \%$ of birds harvested on day 35 with $33 \%$ of the remaining birds harvested on day 47 to maintain live weight density under $36 \mathrm{~kg} / \mathrm{m}^{2}$. may be due to different assumptions in water and feed intake as well as water retention.

Assumptions about the ratio of total water lost from the bird as evaporation and excretion can have a strong influence on the amount of water excreted to litter. By assuming that $80 \%$ of water loss is through evaporation compared to $50 \%$, water excreted to litter reduces by $60 \%$. While a 50:50 ratio (evaporation:liquid) was assumed due to thermo neutral conditions within modern meat chicken sheds, it's more likely that this value will fluctuate daily and throughout the grow-out. Overall, the assumptions used in this study are likely to result in the maximum amount of water being excreted to the litter under normal growing conditions, but it is useful to highlight the quantity of water that can be applied to litter on a daily basis.

Potential users of our equation can use their own production statistics (breed, geographical location, climatic, seasonal, brood and flock thinning specifics) to more accurately estimate water application rates for their operational conditions.

\subsection{Litter water holding capacity and porosity during a grow-out}

Fig. 4 shows the moisture content at saturation, water holding capacity and porosity of litter during the grow-out as the proportion of manure to bedding material increased (data has been standardised for a constant volume and naturally the addition of manure during a grow-out will increase the total amount of litter). Moisture content at saturation (\%) remained relatively constant (71-74\%) during the grow-out, which is similar to previously reported values for wood shavings based litter (63-72\%) (Bilgili et al., 2009; Reed and McCartney, 1970; Miles et al., 2011). Despite the relatively constant moisture content at saturation, the litter on day 31 of the grow-out was able to hold approximately twice the amount of water as the same volume of fresh bedding. The discrepancy exists because the formula for calculating moisture content is sensitive to the increase in dry bulk density of the litter during a grow-out due to manure addition (Reed and McCartney, 1970).

Litter porosity reduced significantly $(\mathrm{p}<0.05)$ between sampling days $0,10,17,25,31$ and 38 but there was no significant difference between days 38, 45 and 52 (Fig. 4). We suggest that the reduction in porosity during the grow-out is due to the accumulation of fine manure particles in the pore space between the coarser pine shavings. Diffusion of water vapour and other gases in and out of the litter through the pores may therefore be restricted later in the grow-out.

\subsection{The amount of water contained within $1.0 \mathrm{~m}^{2}$ of litter}

A significant two way interaction between the length of a growout $\times$ litter moisture content was found to affect the amount of water

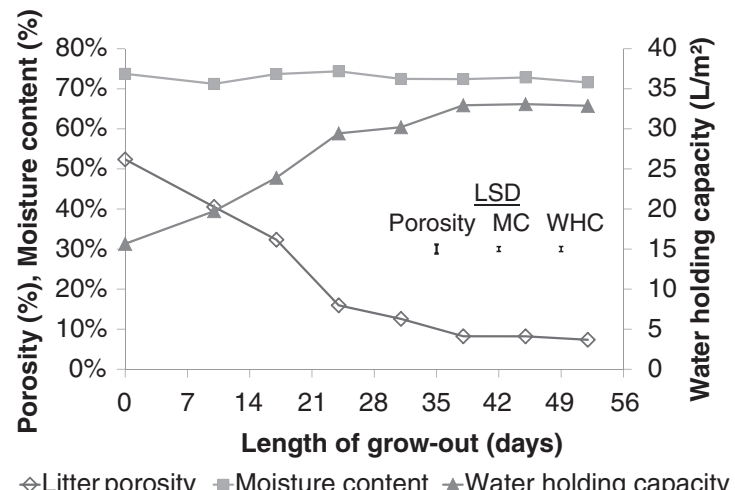

Fig. 4. Moisture content at saturation, water holding capacity and porosity of litter throughout a grow-out (LSD bars show the least significant difference of means at $5 \%$ level). 
contained within $1.0 \mathrm{~m}^{2}$ of litter $(\mathrm{p}<0.001)$. Fig. 5 shows that the amount of water contained within litter increased throughout the grow-out for the same litter moisture content. This suggests that the increased water holding capacity of the litter during the grow-out was due to the increasing manure:bedding ratio. There also appeared to be a trend in the water contained within $1.0 \mathrm{~m}^{2}$ of litter to stabilise between days 31 and 38 of the grow-out (similar to the trend for water holding capacity in Fig. 4), presumably because the manure content outweighed the water holding properties/ability of the original bedding material. To confirm this trend it would be necessary to measure the water content of litter re-used for multiple grow-out cycles. The observed trend of increasing water contained within $1.0 \mathrm{~m}^{2}$ of litter during the grow-out was due to increased water holding ability of the litter material and not due to the increase in litter depth during a grow-out.

The observed increase in water contained within $1.0 \mathrm{~m}^{2}$ of litter is important because it can be related to how quickly the moisture content will change at different stages of a grow-out. Water application to the litter is largely independent of the litter material. If starting from the same moisture content, fresh bedding will reach a higher moisture content than litter later in the grow-out when the same quantity of water is applied. Conversely, when drying more water will need to be evaporated from older litter than fresh bedding to achieve a similar reduction in moisture content (e.g. from $40 \%$ to $20 \%$ ). In general, this might result in greater fluctuations in moisture content earlier in a grow-out.

There is a notable difference in the volume of water contained within $1.0 \mathrm{~m}^{2}$ of litter depending on sample preparation methods. Water holding capacity (Fig. 4) was determined by compacting the sample (as described in AS 3743-2003) whereas the volume of water contained within $1.0 \mathrm{~m}^{2}$ of litter $\left(\mathrm{L} / \mathrm{m}^{2}\right)$ at various moisture contents (\%) (Fig. 5) was determined with samples that were allowed to settle under their own weight ('compacted' versus 'settled', respectively). Maximum water holding capacity of compacted litter was found to be approximately $32 \mathrm{~L} / \mathrm{m}^{2}$ at $71 \%$ moisture content. Extrapolating the moisture content of settled litter to $71 \%$ produced a maximum water holding capacity of approximately $20 \mathrm{~L} / \mathrm{m}^{2}$. It is hypothesised that the actual water holding capacity of poultry litter within a shed will be between these two values due to continuous and alternating actions of compaction and loosening by chickens walking, sitting and scratching the litter.

\subsection{Evaporation rate from litter}

Significant two way interactions were found to affect evaporation rates of water from litter including: length of the grow-out $\times$ moisture content $(\mathrm{p}<0.001)$; air speed $\times$ moisture content $(\mathrm{p}<0.001)$; and length of grow-out $\times$ airspeed $(\mathrm{p}<0.05)$. Litter evaporation rate increased approximately linearly with moisture content (for all litter ages), linearly with air speed (for all litter ages) and also increased with the length of the grow-out. Fig. 6 shows mean evaporation rate increasing approximately linearly with air speed (mean of all litter ages). The observed increase in evaporation rate with air speed (indicated by the slope of the lines) was greatest at high moisture content. (The supplementary material provides an empirical equation to calculate evaporation rates from litter at $25{ }^{\circ} \mathrm{C}$ and $50 \%$ relative humidity with inputs of litter moisture content and air speed. A theoretical approach is also proposed to enable calculation of evaporation rates at other temperature and humidity conditions.)

When litter was relatively dry ( $10 \%$ and $23 \%$ moisture content), evaporation rate remained similar as air speed was increased (from 0.5 to $2.0 \mathrm{~m} / \mathrm{s}$ ); however, at high moisture content ( $47 \%$ and $60 \%$ ) air speed had a much greater effect on the evaporation rate. This result supports the use of higher ventilation air speeds in tunnel-ventilated poultry sheds to accelerate the drying of litter if it becomes wet. Conversely, if litter is maintained in a drier state, there is reduced need for high ventilation air-speed to dry the litter, which may result in energy savings for chicken meat production. There may also be challenges in maintaining dry litter at the peak of the grow-out because evaporation rates from dry litter were found to be less than peak water application rates (water applied to litter at $3.2 \mathrm{~L} / \mathrm{m}^{2} /$ day and evaporated at less than $3.0 \mathrm{~L} / \mathrm{m}^{2} /$ day when litter moisture content was $23 \%$ and experimental air conditions were $25^{\circ} \mathrm{C}$ and $50 \% \mathrm{RH}$ ). Increasing evaporation rate from litter that contains more manure (measured by length of the grow-out) is presumed to be related to greater volume of water per square metre $\left(\mathrm{L} / \mathrm{m}^{2}\right)$ for the same numerical value of moisture content (\%) (Fig. 5).

Only initial evaporation rates (first three hours of drying) were measured during this experiment because it was assumed that regular scratching and turning of the litter surface by bird activity would likely expose fresh litter surfaces that would exhibit the initial evaporation rate. In real production situations, litter is rarely homogeneous and wet excretion from the birds is applied to the litter surface. This wet excretion may or may not be incorporated into the litter but with a high moisture content is likely to have a high evaporation rate.

Evaporation of water has previously been related to the emission of certain gases and odorants (Parker et al., 2010, 2013). In this experiment, evaporation rates from litter were lower than from a free water surface (Fig. 6), indicating that the litter material and pore structure provide some resistance to evaporation. Further research is required to determine whether the factors contributing to higher evaporation rates also contribute to higher gaseous emission rates, and how this may contribute to higher concentration of in-shed gases and/or increased potential for odour impacts to the surrounding community.

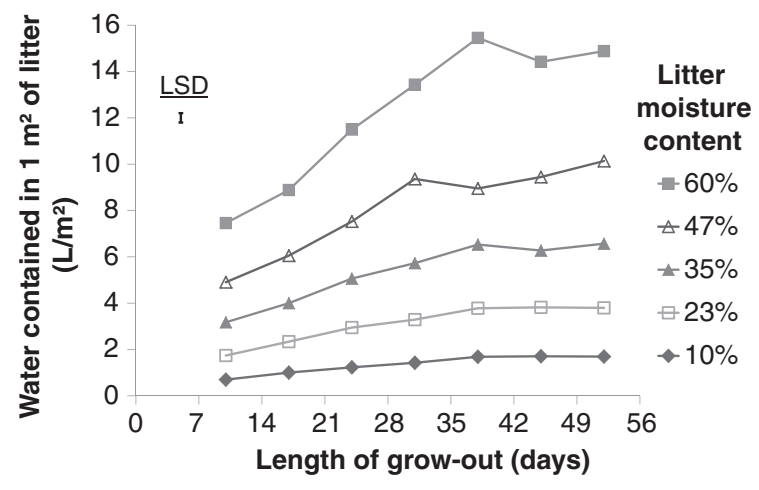

Fig. 5. The volume of water contained within $1.0 \mathrm{~m}^{2}$ of litter at different moisture content values throughout the grow-out assuming a litter depth of $5 \mathrm{~cm}$. (LSD bar shows the least significant difference of means at $5 \%$ level).

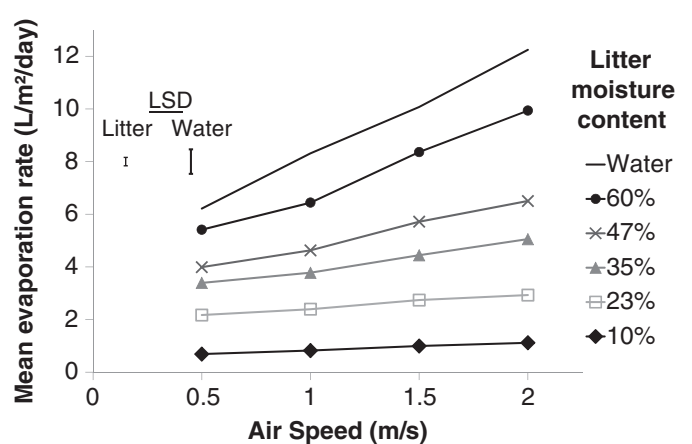

Fig. 6. Evaporation rates from litter (mean for all litter ages, assuming litter depth $5 \mathrm{~cm}$ ) and water (used as an experimental reference material) at $25^{\circ} \mathrm{C}$ and $50 \%$ relative humidity over a range of air speeds. (LSD bars show the least significant difference of means at $5 \%$ level). 


\section{Conclusions}

Litter properties and conditions change constantly within poultry sheds due to manure addition, water application and evaporation. It was found that water holding capacity increased from $15 \mathrm{~L} / \mathrm{m}^{2}$ for fresh pine shavings to just over $30 \mathrm{~L} / \mathrm{m}^{2}$ by day 31 of a grow-out. Conversely, air-filled porosity decreased during the grow-out as fine manure particles accumulated in the pore spaces between the bedding particles. It is suggested that this will increase resistance to gas and water vapour diffusion from deep in the litter profile.

Measuring litter properties to get realistic values can be challenging due to compressibility and varying density. Litter moisture content (\%, gravimetric wet basis) is not a good measure of the amount of water stored in litter $\left(\mathrm{L} / \mathrm{m}^{2}\right)$ if comparing litter materials with different bulk density, such as when bedding materials or manure content differ. We demonstrated that the amount of water stored in litter increased during the grow-out even though the moisture content may be the same.

An equation was developed to calculate the amount of water applied to litter on a daily basis throughout a grow-out. This equation was used to show that water applied to the litter due to bird excretion and normal drinking spillage could be as much as $3.2 \mathrm{~L} / \mathrm{m}^{2} /$ day, with the total amount of water applied to the litter during a grow-out exceeding $100 \mathrm{~L} / \mathrm{m}^{2}$. This is more than three times the water holding capacity of litter, highlighting the importance and necessity of daily evaporation of water from the litter. High daily water:feed ratio, higher stocking density during brooding and use of fresh bedding materials, which have limited capacity to hold water, may result in increased pressure on litter moisture control earlier in the grow-out than is currently anticipated. Recommended ventilation rates throughout the grow-out may require review to ensure that evaporation rates match water application rates at all stages of meat chicken production.

Experiments were conducted to measure evaporation rates from litter during a grow-out. Evaporation rates increased with litter moisture content and air speed. Poultry farm operators with tunnel ventilated sheds may be able to use this to their advantage if there is a need to rapidly dry-out wet litter. When daily moisture application rates are at their greatest, it may be challenging to maintain litter in a very dry state because evaporation rates from dry litter may be insufficient to remove the required amount of water.

Conditions that result in high evaporation rates may also result in high emission rates of certain gases and odours. Further research is required to investigate the relationship between water evaporation and gas emission rates from porous materials such as poultry litter.

\section{Acknowledgements}

This research was conducted within the Poultry CRC, established and supported under the Australian Government's Cooperative Research Centres Programme, as well as the Department of Agriculture and Fisheries (DAF), Queensland Government; and University of New South Wales (UNSW).

The authors would like to thank Jim McAuley and David Mayer for their assistance with the litter moisture, porosity and evaporation experiments and data analysis.

\section{Appendix A. Supplementary data}

Supplementary data to this article can be found online at http://dx. doi.org/10.1016/j.scitotenv.2015.08.092.

\section{References}

Agnew, J.M., Leonard, J.J., 2003. The physical properties of compost. Compost Sci. Util. 11, 238-264.

Aviagen Inc., 2014. Ross 308 Broiler Management Manual.

Bernhart, M., Fasina, O.O., 2009. Moisture effect on the storage, handling and flow properties of poult. litter. Waste Manag. 29, 1392-1398.

Bernhart, M., Fasina, O.O., Fulton, J., Wood, C.W., 2010. Compaction of poultry litter. Bioresour. Technol. 101, 234-238.

Bilgili, S.F., Hess, J.B., Blake, J.P., Macklin, K.S., Saenmahayak, B., Sibley, J.L., 2009. Influence of bedding materials on footpad dermatitis in broiler chickens. J. Appl. Poult. Res. 18, 583-589.

Bolan, N.S., Szogi, A.A., Chuasavathi, T., Seshadri, B., Rothrock, M.J., Panneerselvam, P., 2010. Uses and management of poultry litter. World's Poult. Sci. J. 66, 673-698.

Clarkson, C.R., Misselbrook, T.H., 1991. Odour emissions from broiler chickens. In: Nielsen, V.C., Voorburg, J.H., L'Hermite, P. (Eds.), Odour and Ammonia Emissions from Livestock Farming. Elsevier Science Publishers Ltd., London, pp. 194-202.

Collett, S.R., 2007. Strategies to manage wet litter. 19th Annual Australian Poultry Science Symposium. University Publishing Services, University of Sydney, pp. 134-144.

Collett, S.R., 2012. Nutrition and wet litter problems in poultry. Anim. Feed Sci. Technol. $173,65-75$.

de Jong, I.C., van Harn, J., Gunnink, H., Hindle, V.A., Lourens, A., 2012. Footpad dermatitis in Dutch broiler flocks: prevalence and factors of influence. Poult. Sci. 91, 1569-1574.

Elliott, H.A., Collins, N.E., 1982. Factors affecting ammonia release in broiler houses. Trans. ASAE 25, 413-418.

Eriksson De Rezende, C.L., Mallinson, E.T., Tablante, N.L., Morales, R., Park, A., Carr, L.E., Joseph, S.W., 2001. Effect of dry litter and airflow in reducing Salmonella and Escherichia coli populations in the broiler production environment. J. Appl. Poult. Res. 10, 245-251

Feddes, J., Emmanuel, E., Zuidhoft, M., 2002. Broiler performance, body weight variance, feed and water intake, and carcass quality at different stocking densities. Poult. Sci. 81, 774-779.

Goldstein, D.L., Skadhauge, E., 2000. Chapter 11 - renal and extrarenal regulation of body fluid composition. In: Whittow, G.C. (Ed.), Sturkie's Avian Physiology, Fifth Edition Academic Press, San Diego, pp. 265-297.

Hudson, N., Ayoko, G.A., 2008. Odour sampling 1: physical chemistry considerations. Bioresour. Technol. 99, 3982-3992.

Liu, Z., Wang, L., Beasley, D., 2007. Effect of moisture content on ammonia emissions from broiler litter: a laboratory study. J. Atmos. Chem. 58, 41-53.

Manning, L., Chadd, S.A., Baines, R.N., 2007. Water consumption in broiler chicken: a welfare indicator. World's Poult. Sci. J. 63, 63-71.

Miles, D.M., Rowe, D.E., Cathcart, T.C., 2011. Litter ammonia generation: moisture content and organic versus inorganic bedding materials. Poult. Sci. 90, 1162-1169.

Murphy, K.R., Parcsi, G., Stuetz, R.M., 2014. Non-methane volatile organic compounds predict odor emitted from five tunnel ventilated broiler sheds. Chemosphere 95, 423-432.

Parker, D.B., Caraway, E.A., Rhoades, M.B., Cole, N.A., Todd, R.W., Casey, K.D., 2010. Effect of wind tunnel air velocity on VOC flux from standard solutions and CAFO manure/ wastewater. Trans. ASABE 53, 831-845.

Parker, D., Ham, J., Woodbury, B., Cai, L., Spiehs, M., Rhoades, M., Trabue, S., Casey, K., Todd, R., Cole, A., 2013. Standardization of flux chamber and wind tunnel flux measurements for quantifying volatile organic compound and ammonia emissions from area sources at animal feeding operations. Atmos. Environ. 66, 72-83.

Reed, M.J., McCartney, M.G., 1970. Physical properties of selected litter materials and performance of broiler chickens. Ga. Agric. Exp. Sta. Res. Bull. 75, 75 (Mar).

Roumeliotis, T.S., Dixon, B.J., Van Heyst, B.J., 2010. Characterization of gaseous pollutant and particulate matter emission rates from a commercial broiler operation part II: correlated emission rates. Atmos. Environ. 44, 3778-3786.

Shepherd, E.M., Fairchild, B.D., 2010. Footpad dermatitis in poultry. Poult. Sci. 89, 2043-2051.

Standards Australia, 2003. Potting Mixes (AS 3743-2003). Australian/New Zealand Standards (Standards Australia/Standards New Zealand, Sydney).

Tucker, S.A., Walker, A.W., 1992. 2 - hock burn in broilers. In: Garnsworthy, P.C., Haresign, W., Cole, D.J.A. (Eds.), Recent Advances in Animal Nutrition. Butterworth-Heinemann, pp. 33-50.

VSN, 2014. GenStat for Windows. 16th edition. VSN International, Hemel Hempstead, UK (Web page: GenStat.co.uk).

Wadud, S., Michaelsen, A., Gallagher, E., Parcsi, G., Zemb, O., Stuetz, R., Manefield, M., 2012. Bacterial and fungal community composition over time in chicken litter with high or low moisture content. Br. Poult. Sci. 53, 561-569.

Watkins, S., Tabler, G.T., 2009. Broiler Water Consumption. The Poultry Site.

Williams, C.L., Tabler, G.T., Watkins, S.E., 2013. Comparison of broiler flock daily water consumption and water-to-feed ratios for flocks grown in 1991, 2000-2001, and 2010-2011. J. Appl. Poult. Res. 22, 934-941.

Yahav, S., Straschnow, A., Luger, D., Shinder, D., et al., 2004. Ventilation, sensible heat loss, broiler energy, and water balance under harsh environmental conditions1. Poult. Sci. $83,253-258$. 